\title{
The role of interleukin-6-STAT3 signalling in glioblastoma (Review)
}

\author{
ALICE J. WEST ${ }^{1 *}$, VANESSA TSUI ${ }^{1 *}$, STANLEY S. STYLLI ${ }^{1,2}$, HONG P.T. NGUYEN $^{1}$, \\ ANDREW P. MOROKOFF ${ }^{1,2}$, ANDREW H. KAYE ${ }^{1,2}$ and RODNEY B. LUWOR ${ }^{1}$ \\ ${ }^{1}$ Department of Surgery, The University of Melbourne; ${ }^{2}$ Department of Neurosurgery, \\ The Royal Melbourne Hospital, Parkville, VIC 3050, Australia
}

Received November 30, 2017; Accepted April 26, 2018

DOI: $10.3892 / 01.2018 .9227$

\begin{abstract}
Glioblastoma is the most common type of malignant brain tumor among adults and is currently a non-curable disease due primarily to its highly invasive phenotype, and the lack of successful current therapies. Despite surgical resection and post-surgical treatment patients ultimately develop recurrence of the tumour. Several signalling molecules have been implicated in the development, progression and aggressiveness of glioblastoma. The present study reviewed the role of interleukin (IL)-6, a cytokine known to be important in activating several pro-oncogenic signaling pathways in glioblastoma. The current study particularly focused on the contribution of IL-6 in recurrent glioblastoma, with particular focus on glioblastoma stem cells and resistance to therapy.
\end{abstract}

\section{Contents}

1. Introduction

2. Interleukin-6 signalling in glioblastoma

3. Glioblastoma stem cells

4. Therapeutic targets in recurrent glioblastoma

5. Mechanism of STAT3 action in recurrent glioblastoma

6. Conclusions

\section{Introduction}

Gliomas are histologically divided into four main grades based on World Health Organisation (WHO) criteria. Grade II

Correspondence to: Dr Rodney B. Luwor, Department of Surgery, The University of Melbourne, The Royal Melbourne Hospital, Level 5, Clinical Sciences Building, Royal Parade Street, Parkville, VIC 3050, Australia

E-mail: rluwor@unimelb.edu.au

*Contributed equally

Key words: IL-6, STAT3, glioblastoma, therapeutics astrocytomas are known as diffuse astrocytomas, while grade III are anaplastic astrocytomas (AA) and are considerably more proliferative and infiltrative than grade II gliomas (1). Yet, grade IV astrocytomas or glioblastoma, despite being histologically similar to AA, are notably more proliferative, invasive and angiogenic (2). Glioblastoma is the most common and aggressive tumour of the central nervous system, and it represents $17 \%$ of all primary intracranial tumours (3). The current standard of treatment for patients with glioblastoma is maximal surgical resection, concurrent and adjuvant temozolomide and radiotherapy (known as the Stupp protocol) (4). Despite this standard of care treatment, the median survival is less than 15 months, median progression-free survival is less than 7 months and 5-year survival rate of treated patients is about $10-20 \%(4,5)$.

The tumour microenvironment plays numerous key roles in cancer progression including the release of cytokines and other effectors that mediate responses and events that aid in tumour growth $(6,7)$. These cytokines promote factors that are central to cancer formation and progression, incorporating sustained growth, cell migration, inhibition of apoptosis and differentiation of tumour cells. It is well established that the IL-6-STAT3 signalling pathway, along with other inflammatory cytokines such as IL1 $\beta$, IL-23 and TNF $\alpha$ has been implicated in cancer progression in many tumour types including glioblastoma contributing to tumour resistance and recurrence of glioblastoma (8).

\section{Interleukin-6 signalling in glioblastoma}

Interleukin-6 (IL-6). The ligand IL-6 is a pleiotropic cytokine of about $25 \mathrm{kDa}$ (9). It was first discovered as a B cell differentiation factor (BSF-2), which induces maturation of $\mathrm{B}$ cells, but has since been identified as having an important role in inflammation-linked cancers, including prostate, breast, gastric, colon, lung and brain (10). IL-6 is often expressed when there are stimuli that are associated with tissue damage or stress, such as UV, viruses and the expression of other pro-inflammatory cytokines (11-13). It can be overexpressed during inflammation as an acute-phase response (14). During this inflammatory response, tumour necrosis factor alpha (TNF $\alpha$ ) induces the expression of IL-6 (15). IL-6 subsequently regulates the inflammatory response by decreasing the expression of other pro-inflammatory cytokines along 
with up-regulating anti-inflammatory cytokines, such as IL-1 $(15,16)$. IL-6 has also been shown to inhibit TNFa expression (17), demonstrating its pleiotropic nature.

IL-6 is part of the IL- 6 cytokine family, which consist of IL-11, IL-27, leukaemia inhibitor factor (LIF) and oncostatin M (OSM) (18). They share the common co-receptor (gp130 $\beta$ subunit), which is expressed in almost every tissue and organ in the body. It is this subunit that is responsible for the transmission of signalling into the cell by activating associated cytoplasmic tyrosine kinases (e.g. JAK), resulting in the phosphorylation of various transcription factors including STAT3 $(18,19)$. Among the family of IL- 6 cytokines, attention has focussed on IL-6 itself, as its expression levels is highly up-regulated and has been shown to be correlated with poor survival in many cancers.

IL-6 triggered JAK-STAT3 signaling in glioblastoma. IL-6 binds and signals through its own distinct receptor alpha subunit (IL-6R $\alpha ; 80 \mathrm{kDa}$ ) on the plasma membrane (20). This IL-6/IL-6R $\alpha$ complex then associates with the shared IL-6 family co-receptor gp130, resulting in an activated hexameric complex (two molecules of IL-6, two molecules of IL-6Ra and two molecules of gp130). There are two types of IL-6 mediated signalling: Classical and trans-signalling. Classical IL-6 signalling is the major form of IL-6 signalling and the membrane-bound IL-6R (mIL-6R $\alpha$ ) which is only expressed in certain tissues such as hepatocytes, some epithelial cells and leukocytes (21). Alternatively, the trans-signalling mechanism allows IL-6 signalling to occur in more cell types, as gp130 is expressed ubiquitously. This occurs due to trans-signalling of soluble IL-6R $\alpha$ (sIL-6R $\alpha$ ), which lacks the trans-membrane domain, through the interaction with gp130. sIL-6R $\alpha$ is then generated by the alternative splicing of the IL-6R $\alpha$ mRNA by cytoplasm-bound metalloproteinases (ADAM10 and ADAM17) $(18,22-24)$. As a result, the presence of sIL-6R $\alpha$ permits IL-6 signalling to occur in adjacent cells. Both signalling pathways lead to the activation of JAK proteins, which are responsible for intracellular signalling and the subsequent phosphorylation of STAT transcription factors, in particular STAT3 (25).

Several studies demonstrate a correlation with IL-6 expression with glioma tumour grade and overall patient survival. IL-6 mRNA expression was found to be significantly greater in glioblastoma patient samples compared to those with lower histopathological grade (including Grade II and III astrocytomas and Grade I pilocytic astrocytomas; Table I) (26). In addition, no IL-6 gene amplification was detected in low-grade or anaplastic tumors (0/17), whereas amplification was found in 15 out of 36 (42\%) glioblastoma sections (27). Importantly, this IL-6 gene amplification correlated with significantly shorter survival compared to glioblastoma patients without amplification (27). In addition, immunohistochemistry analysis identified the IL-6 receptor expression in 6/6 (100\%) patient glioblastoma samples compared to 0/7 (0\%) in normal brain tissue (28). IL-6 has also been detected in the cerebrospinal fluid of $11 / 13(85 \%)$ and the tumor cyst fluid of 5/5 (100\%) glioblastoma patients (29). In contrast, only 3/16 (19\%) cerebrospinal Fluid (CSF) samples obtained from control patients had detectable IL-6 levels (29).

Once IL- 6 has bound, the $\beta$ subunit (gp130) homodimerises and the receptor-associated Janus Kinase (JAK1, JAK2 and Tyk2) become activated (18). Activated JAKs act as a platform for phosphorylation of STAT3. Two STAT3 monomers can form a dimer and up-regulate STAT3 target genes in the nucleus (Fig. 1). The STAT protein family is a group of transcription factors that play crucial roles in the transmission of extracellular signals into the nucleus for the transcription of a variety of genes $(30,31)$. In cancer research, there is particular focus on STAT3 because of its oncogenic abilities. STAT3 up-regulates genes that can facilitate tumour survival, angiogenesis, resistance to cell death and cell cycle progression. Target genes of STAT3 include vascular endothelial growth factor (VEGF), Bcl-2, Bcl-xL, cyclin D1, human telomerase reverse transcriptase and c-myc (30).

Involvement of STAT3 in tumourigenesis was first described in fibroblasts and epithelial cells that were transformed by Src tyrosine kinase, where constitutive STAT3 activity was first observed $(32,33)$. This was further supported in transgenic mice (transformed with v-src), where they developed astrocytoma that led to secondary glioblastoma (34). It only became clear that STAT3 itself could be implicated in cancer when it was found that dominant-negative STAT3 decreased tumourigenesis behaviour of $s r c$-transformed cells, whereas constitutively active STAT3 enhanced tumourigenesis $(32,35,36)$. Interestingly, mutations within the STAT3 gene are rare, indicating that constitutive activation of STAT3 is usually due to abnormal signalling from upstream regulators, such as IL-6 (33).

STAT3 is activated in a high percentage of glioblastoma (37-39). It contributes to tumourigenesis in glioblastoma by inhibiting apoptosis, which has been demonstrated by the use of RNAi knockdowns and STAT3 inhibitors $(39,40)$. It has also been observed that recurrent glioblastoma tumours exhibit increased phosphorylated STAT3 levels when compared with primary glioblastoma (41). Moreover, tumors which exhibited greater nuclear localization of STAT3 correlated with lower rates of recurrence-free survival and overall patient survival.

Interestingly, another study reported that the down-modulation of pSTAT3-Y705 resulted in resistance to Temozolomide, as it was able to minimise $\mathrm{O}^{6}$-methylguanine DNA methyltransferase (MGMT) expression post-transcriptionally in recurrent glioblastoma (41). It was observed in this study that STAT3 inhibition reduced MGMT levels, which led to the re-sensitisation to Temozolomide treatment (41). Potential therapies utilising STAT3 as a target are currently being investigated and clinical trials are underway for pSTAT3-Y705 inhibitors (42).

\section{IL-6 signalling in glioma development and cell invasion and} migration. It is well established that IL-6 signalling plays a crucial role in a variety of cancers, whereby expression levels of IL- 6 mRNA and protein are significantly increased in colorectal (43), prostate (44), breast (45), ovarian (46), pancreatic $(46,47)$, lung (48) and cervical cancer (49). Weissenberger and colleagues showed the importance of IL-6 signalling in glioma and its impact on the tumorigenicity in glioblastoma, using transgenic mice (50). Mice expressing the GFAP-v-src $\mathrm{st}^{+-}$ transgene develop spontaneous astrocytomas with a penetrance of around $21 \%$ (12 out of 56). However, only 1 out of 35 transgenic mice (3\%) that lack IL-6 developed astrocytic tumour formation (50). 
Table I. Percentage of positive detected IL-6 in human primary brain tumor samples by histopathological grade.

\begin{tabular}{lllccr}
\hline Author, date & \multicolumn{1}{c}{ Evaluation } & Technique & $\begin{array}{c}\text { Brain tumour } \\
(\text { Grade I-III) }(\%)\end{array}$ & $\begin{array}{c}\text { Glioblastoma } \\
\text { (Grade IV) }(\%)\end{array}$ & (Refs.) \\
\hline Rolhion et al, 2001 & IL-6 mRNA expression & RT-PCR & $7 / 16(44)$ & $38 / 43(88)$ & $(26)$ \\
Rolhion et al, 2001 & IL-6 protein expression & IHC & N/A & $4 / 5(80)$ & $(26)$ \\
Tchirkov et al, 2007 & IL-6 gene amplification & FISH & $0 / 17(0)$ & $15 / 36(42)$ & $(27)$ \\
Giometto et al, 1996 & IL-6 protein expression & IHC & $3 / 10(30)$ & $4 / 4(100)$ & $(113)$ \\
Chang et al, 2005 & IL-6 protein expression & IHC & N/A & $5 / 11(56)$ & $(114)$ \\
Sasaki et al, 2001 & IL-6 mRNA expression & RT-PCR & $8 / 20(40)$ & $8 / 9(89)$ & $(115)$ \\
Sasaki et al, 2001 & IL-6 protein expression & IHC & N/A & $4 / 7(57)$ & $(115)$ \\
\hline
\end{tabular}

IL-6, interleukin-6; IHC, immunohistochemistry; RT-PCR, reverse transcription-polymerase chain reaction; N/A, not applicable; FISH, fluorescent in situ hybridization.

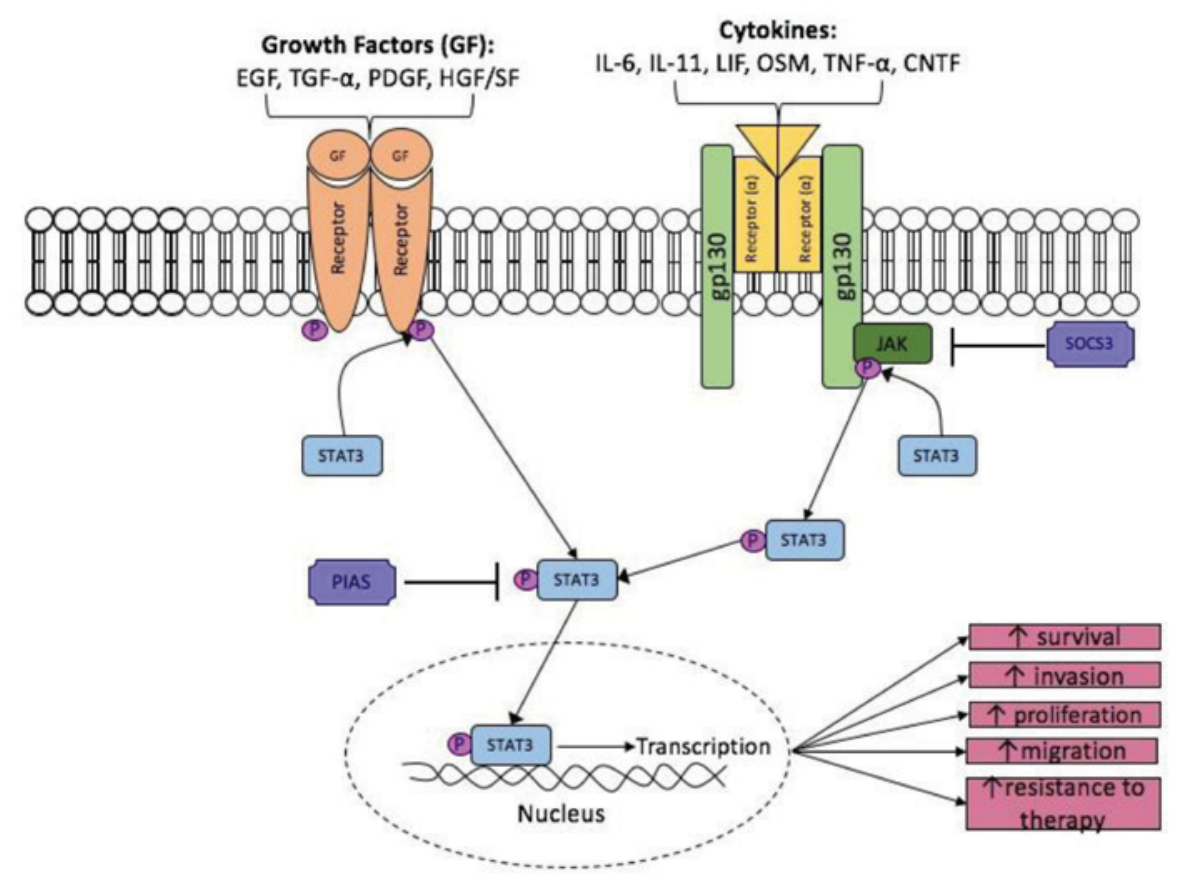

Figure 1. STAT3 activation pathway. STAT3 is activated through the interaction of cytokines and growth factors. Growth factors have intrinsic kinase activity, whereas the receptors of ligands have associated JAK that, when phosphorylated, acts as a platform for un-phosphorylated STAT3 to become activated. Phosphorylated STAT3 dimers (not shown in figure for simplicity) translocates to the nucleus where it up-regulates a variety of genes that can contribute to tumourigenesis. The STAT3 pathway is negatively regulated by a number of ways. SOCS3 inhibits the phosphorylation of JAK proteins and PIAS3 inhibits dimerisation of STAT3 monomers. Phosphorylated STAT3 dimers are not shown for simplicity.

IL-6 signalling promotes a variety of activities that support gliomagenesis including cell invasion and migration, contributing to the invasive nature of glioblastoma, resulting in reduced treatment efficacy and high rates of recurrence. STAT3 activation induced by IL-6 signalling has been shown to promote cell invasion and migration in U251 and T98G glioblastoma cells (51). In a study by Liu et al (51), increased levels of IL-6 positively correlated with the levels of matrix metalloproteinase-9 (MMP-9) expression. MMPs belong to a family of proteases responsible for degrading extracellular matrix proteins and play a major role in migration (both adhesion and dispersion) as well as cell proliferation. Similarly, a study by Li et al (52), demonstrated IL-6 stimulation of
U87MG glioblastoma cells resulted in increased MMP-2 expression and secretion and enhanced cell invasion.

Furthermore, IL-6 signalling correlates with increased fascin-1 expression. Fascin-1 is involved in cell invasion by the formation of actin-based protrusions known as invadopodia and the subsequent degradation of the extracellular matrix to promote migration and invasion (52). Immunofluorescence staining of fascin-1 revealed that the number of protrusions increased and fascin-1 protein was localised to the peripheries of the cell when glioblastoma cells were treated with IL-6. This study demonstrated that IL-6 signalling influences the distribution of fascin- 1 and alters the structural aspects of the cell to become a more invasive phenotype in glioblastoma cells (51). 
IL-6 signalling and tumour angiogenesis. Tumour angiogenesis is another crucial process that is required for the growth and invasion of tumours. Angiogenesis requires migration of vascular endothelial cells into the tumour bulk (51). This process involves the release of mediators such as TNF- $\beta$, TNF- $\alpha$, MMP-9, MMP-2 and VEGF (53). The STAT3 transcription factor is known to up-regulates the expression of VEGF-2 and its receptor, VEGFR-2, contributing to invasion through the action of IL-6 signalling and subsequent JAK-STAT3 activation (54-56). IL-6 secretion into neighbouring cells further induces this behaviour, thereby promoting cell migration through these vascular endothelial cells (51).

VEGF is an important mediator in tumour-induced angiogenesis. It has been observed that high expression of VEGF correlates with higher tumour grade and shorter survival $(57,58)$, while one of the mechanisms of progression in glioblastoma is postulated to involve tumour resistance to anti-angiogenic treatments $(59,60)$. This may be due to these angiogenic switches and up-regulation of different angiogenic pathways (57,61-63) as well as mesenchymal cell transition (64).

Another essential pro-angiogenic factor is fibroblastic growth factor-2 (FGF-2), which is a heparin-binding protein that has a range of roles, including serving an important pathway in tumorigenesis (65). Recent research has indicated that both VEGF and FGF2 work together to influence the process of angiogenesis. It has been shown that when both factors are expressed in mouse models, there is enhanced tumour growth coupled with the presence of high density vessels. When either FGF2 or VEGF signalling is inhibited, the rate of the tumour growth decreases significantly (65-67). Although an early study (20) showed that IL-6 acts as a growth factor in glioblastoma, a more recent study did not reach this conclusion and demonstrated that IL- 6 did not have a proliferative effect in GBM cell lines, but instead promoted a more invasive phenotype by increasing the migration ability of cells (51).

IL-6 signalling promotes resistance to cell death. In addition to evading growth suppression signaling through the loss of TP53 function, tumours such as glioblastoma are also associated with an increase in the expression of anti-apoptotic regulators or down-regulation of pro-apoptotic factors. IL-6 signalling disrupts the balance between anti- and pro-apoptotic protein expression by favouring anti-apoptotic signalling through JAK-STAT3 activation, as well as NF-kB signalling, which activates the expression of many anti-apoptotic proteins such as Bcl-2, Bcl-xL and Mcl-1 $(51,68)$. These anti-apoptotic proteins are also important in cell proliferation as they are direct targets of STAT3 (69). Other than increased Bcl-2 and Bcl-xL expression, IL-6 also promotes the expression of survivin through JAK-STAT3 activation $(69,70)$. It has been found that the downregulation of survivin by inhibiting STAT3 induces apoptosis in tumour cells (70).

\section{Glioblastoma stem cells}

Cancer stem cells (CSCs) are a group of tumour cells that have stem cell-like properties and are capable of self-renewal. Studies have shown that CSCs are critical in the progression of cancer and resistance to various therapies in different types of solid tumours, including brain tumours (71-76). In recent years the cancer stem cell (CSC) hypothesis has grown in popularity. This states that a small group of cells can maintain the cancer growth and survival, whilst providing resistance to therapy. It has been established that gliomas are one of the tumours where cancer stem cells, or glioma stem cells (GSCs) has been established (77,78). Subsequently, GSCs have been intensely studied for understanding their capacity for self-renewal and importantly, their contribution to therapeutic resistance as well as tumour recurrence (79). GSCs are thought to play important roles in gliomagenesis, recurrence and aggressiveness $(80,81)$.

In other cancers, IL- 6 is also implicated in promoting STAT3 mediated CSC expansion, such as in prostate and breast CSCs (82-84). Through the activation of JAK-STAT3 signalling (mainly from IL-6 signalling), hypoxic conditions activate these CSCs and promote self-renewal (85). It was found that upon STAT3 inhibition, GSCs lose their stem-cell phenotype permanently, suggesting that STAT3 is required for the self-renewal and growth of stem cells within glioblastoma $(40,86)$. The contribution of CSCs to the difficulty of cancer treatment and therapy is crucial, and targeting the JAK-STAT3 pathway may therefore become a potential mechanism to overcome CSC-mediated Temozolomide resistance in glioblastoma and other solid tumours.

Several studies have found that GSCs express the IL-6 receptor and ligand, which indicates that IL- 6 could be a potential cytokine to contribute to the tumourigenicity of these GSCs. Wang et al (2009) (87) found that GSCs co-expressed elevated levels of IL-6R $\alpha$ and gp130 ( $\beta$ subunit), as demonstrated by immunofluorescence staining, although they also showed that IL-6 mRNA levels were lower in GSCs that non-GSCs. Knockdown of IL- 6 or IL-6R $\alpha$ by shRNA led to reduced cell growth, neurosphere formation and increased cell death in GSCs isolated from D456MG human glioma xenografts. IL-6 or IL-6R $\alpha$ suppression also led to reduced tumour growth and increased survival of mice bearing intracranial xenografts (87). IL-6 has also been shown to induces the expression of glioma pathogenesis-related 1 (GPR1, also known as RTVP1) via the STAT3 pathway (88). GPR1 plays an important role in GSCs, contributing to migration, resistance to therapy and tumour recurrence. GPR1 was originally discovered in glioblastoma as one of the target genes of the tumour suppressor gene p53, one of the most commonly mutated genes in human cancer.

STAT3 has been shown to be highly expressed in GSCs, and inhibition of STAT3 levels has led to decreases in the proliferation of these GSCs (40). Furthermore, inhibition of STAT3 also diminishes the multipotency characteristic of these GSCs. STAT3 has been identified as a potential target for CSC-mediated therapy as it is the convergence point for many signaling pathways. It has been found that inhibition of STAT3 using a shRNA approach prevented proliferation and formation of neurospheres in GSCs $(30,40,89)$. Moreover, leukaemia inhibitory factor (LIF), a member of the IL- 6 family, has been found to be responsible for the tumour development of GSCs via the JAK-STAT pathway (90).

\section{Therapeutic targets in recurrent glioblastoma}

The importance of targeting the STAT3 signalling pathway due to its function in recurrence, GSCs and resistance to 
Table II. Therapeutic agents targeting JAK/STAT3 in the glioblastoma setting.

\begin{tabular}{|c|c|c|c|c|}
\hline Author, date & Drug name & Target & Findings & (Refs.) \\
\hline Ashizawa et al, 2013 & STX-0119 & STAT3 & $\begin{array}{l}\text { Reduced cell growth and induced apoptosis in vitro } \\
\text { and reduced tumour growth in vivo }\end{array}$ & $(30)$ \\
\hline Rahaman et al, 2002 & WP1066 & JAK2/STAT3 & Reduced cell growth in vitro and in vivo & $(39)$ \\
\hline Hussain et al, 2007 & WP1066 & JAK2/STAT3 & Reduced cell growth in vitro and in vivo & $(116)$ \\
\hline Iwamaru et al, 2007 & WP1066 & JAK2/STAT3 & Reduced cell growth in vitro and in vivo & $(117)$ \\
\hline Stechishin et al, 2013 & WP1066 & JAK2/STAT3 & Reduced cell growth in vitro and in vivo & $(118)$ \\
\hline McFarland et al, 2011 & AZD1480 & JAK $1 / 2$ & $\begin{array}{l}\text { Reduced cell growth and induced apoptosis in vitro, } \\
\text { reduced tumour growth in vivo and enhanced } \\
\text { survival of mice bearing intracranial tumours }\end{array}$ & $(119)$ \\
\hline He et al, 2013 & G5-7 & JAK2 & Reduced cell growth in vitro and in vivo & $(120)$ \\
\hline Senft et al, 2011 & AG490 & JAK2 & $\begin{array}{l}\text { Reduced cell Proliferation, } \\
\text { migration and invasion in vitro }\end{array}$ & $(121)$ \\
\hline Lo et al, 2008 & JSI-124 & JAK2/STAT3 & $\begin{array}{l}\text { Reduced cell growth and } \\
\text { induced apoptosis in vitro }\end{array}$ & $(122)$ \\
\hline Mukthavaram et al, 2015 & SAR317461 & JAK2/STAT3 & $\begin{array}{l}\text { Reduced cell growth and induced } \\
\text { apoptosis and autophagy in vitro }\end{array}$ & $(123)$ \\
\hline Fuh et al, 2009 & LLL3 & STAT3 & $\begin{array}{l}\text { Reduced cell growth and induced } \\
\text { apoptosis in vitro and enhanced survival } \\
\text { of mice bearing intracranial tumours }\end{array}$ & $(124)$ \\
\hline Ball et al, 2011 & LLL12 & STAT3 & $\begin{array}{l}\text { Reduced cell growth and migration } \\
\text { and induced apoptosis in vitro }\end{array}$ & $(125)$ \\
\hline Sai et al, 2012 & WP1193 & STAT3 & Reduced cell growth in vitro and in vivo & $(126)$ \\
\hline Han et al, 2016 & Cpd 188 & STAT3 & Reduced cell growth in vitro and in vivo & $(127)$ \\
\hline
\end{tabular}

JAK2, Janus kinase 2; STAT3, signal transducer and activator of transcription 3.

Temozolomide is well established (90). Therapeutic targets of STAT3 have been investigated, but only a small number has been tested against glioblastoma (summarised in Table II). Furthermore, there has not been much success at preventing downstream nuclear signalling (91). Studies into STAT3 inhibitors should continue, as the importance of this pathway is continually being demonstrated $(92,93)$. Furthermore, the inhibitors that have been investigated with glioblastoma generally have had significant challenges in the translation into clinical practice, mainly because of the form of administration, toxicity, cell permeability and non-selective activity (91).

The disruption of upstream receptor tyrosine kinases is one of the potential methods for inhibiting STAT3 activity. By inhibiting JAKs, growth factor receptors, receptor tyrosine kinases (RTKS) and cytokine receptors, it would be possible to alter downstream STAT3 activity. However, STAT3 is the convergence point of several oncogenic signalling pathways, including EGFR, heregulin-2/neuregulin receptor (Her2/Neu), Platelet Derived Growth factor receptor, IL-6R/gp130, c-Met, Abelson Leukemia protein (Abl), and Src tyrosine kinases. Therefore, it would be probable that a compensatory pathway could override the initial inhibition of STAT3 (94-98). On the other hand, preventing homodimersation of STAT3 involves blocking the SH2 domains from coming together after
STAT3 phosphorylation, and ultimately inhibiting STAT3's transcription capabilities. Thus far, studies have targeted the SH2 domain to prevent homodimerisation (99-102). Two groups $(100,101)$ have shown that blocking the phosphorylated tyrosine peptide at position 705 was able to prevent STAT3 from binding to DNA in the nucleus and furthermore, the $\mathrm{SH} 2$ domain of STAT3 has been shown to interact with upstream signalling proteins to STAT3, including EGFR and IL-6 and its receptor. Studies that have targeted this particular homodimerisation have generated positive results, yet they have yet to be translated into an in vivo setting (28,103-105).

\section{Mechanism of STAT3 action in recurrent glioblastoma}

JAK/STAT activation. There is a lack of evidence regarding the mechanism of action of over-activation of STAT3 in recurrent glioblastoma. The STAT3 signalling pathway has been extensively investigated in primary glioblastoma, but it has not yet been shown why phosphorylated STAT3 is overexpressed in recurrent glioblastoma compared to primary glioblastoma (44). Furthermore, increased phosphorylation of STAT3 has been correlated with increased grade of astrocytoma $(106,107)$. Based on this evidence, it is possible that STAT3 could be considered as a prognostic factor. Tu et al (107), have demonstrated that 


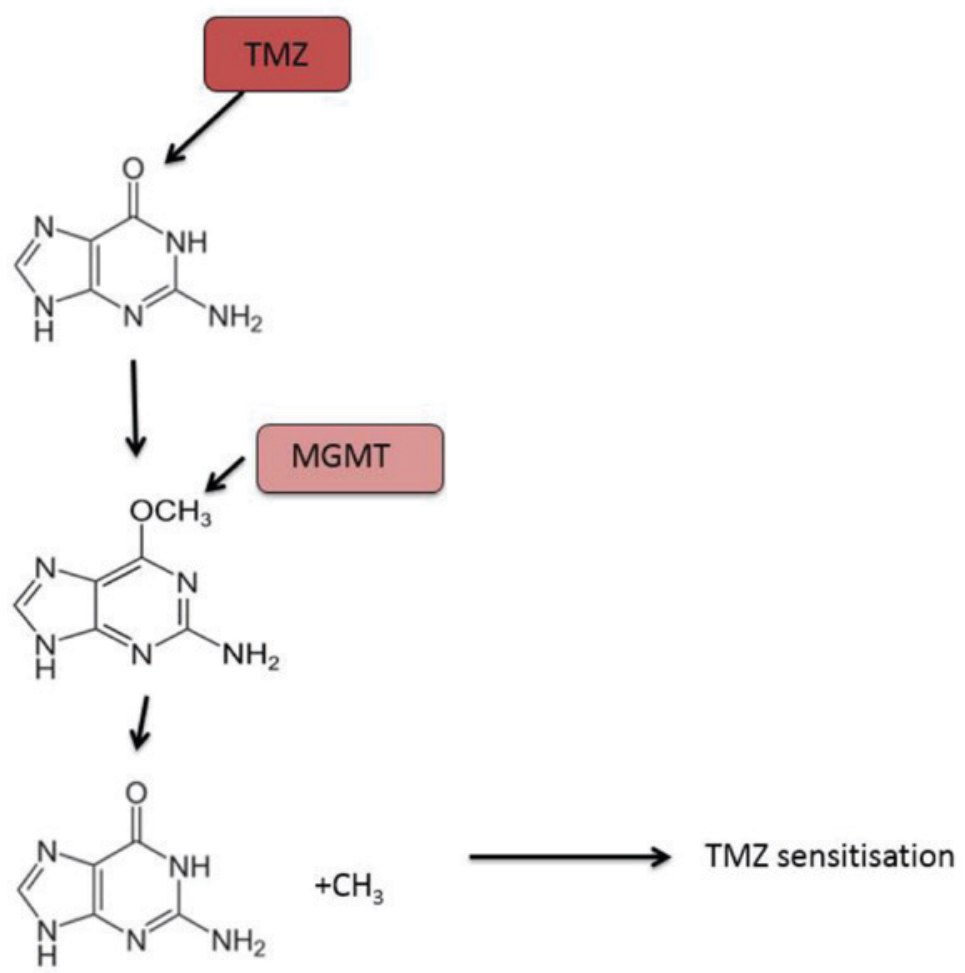

Figure 2. TMZ is an alkylating agent that induces DNA methylation of guanine at the $\mathrm{O}^{6}$ position causing double-stranded DNA breaks and ultimately cell death. MGMT is a DNA-repair protein that counteracts the apoptotic effects of temozolomide by removing alkyl groups from the $\mathrm{O}^{6}$ position of guanine enhancing cell survival. Thus glioblastoma with high MGMT expression are commonly refractory to temozolomide while glioblastoma with silenced MGMT through epigenetic methylation of the MGMT promoter display greater sensitivity to temozolomide. TMZ, Temozolomide; MGMT, O6-methylguanine DNA methyltransferase.

JAK/STAT activation is correlated to higher grade gliomas, and furthermore, it was shown that JAK/STAT activation is a prognostic indicator of decreased survival. One potential mode of action is through a mutated MSH6 gene, which has been correlated with a methylated O6-methylguanine-DNA transferase (MGMT) promoter, whose cellular levels are known to be regulated by STAT3 through IL-6 (41). This potential mechanism is outlined in the next section.

IL-6-STAT3 signaling and MGMT. Currently, the DNA repair protein, MGMT, is the most studied predictive biomarker of response to temozolomide treatment in patients with glioblastoma. Temozolomide exerts its cytotoxic activity by methylating specific DNA sites including the $\mathrm{O}^{6}$ position of the nucleotide guanine, resulting in cell death (108). MGMT directly inhibits the cytotoxic effect of temozolomide by removing the methyl group off the $\mathrm{O}^{6}$ position of guanine in DNA $(109,110)$. Thus, patients with glioblastoma that expressed reduced MGMT due to epigenetic methylation of the MGMT promoter have better response rates to temozolomide and are associated with longer overall survival (Fig. 2) (111).

A study by Piperi et al (112) identified methylation of MGMT in 58.8\% of tissue surgically resected from 23 glioblastoma patients. Patients with tumour tissue containing MGMT methylation had a poorer overall median survival of 12 months compared to patients with tissue absent of MGMT methylation (16 months). Importantly, MGMT methylation in this study was found to also correlate with IL-6 expression (112). Despite this paper not examining STAT3 activity, one can speculate that enhanced STAT3 activation (through increased IL-6 expression) may mediate temozolomide sensitivity and poorer overall outcomes.

In support of this notion is the study from Koksaka and colleagues who did indeed evaluate a potential correlation between phosphorylated STAT3 and MGMT expression (41). In this paper, a significant correlation was observed between pSTAT3 staining intensity by immunohistochemistry with MGMT expression in 44 surgically resected human glioma specimens. Koksaka and colleagues also generated a U87MG sub-population that was temozolomide-refractory after 3 weeks of continuous exposure to low-dose temozolomide. These resistant cells designated U87R displayed greater expression of IL-6, STAT3 and MGMT compared to their sensitive parental counterparts. Importantly, pharmacological inhibition of STAT3 or STAT3 knockdown with shRNA resulted in reduced MGMT expression in the U87R cells and other glioblastoma cell lines. STAT3 inhibition also re-sensitized cells to temozolomide (41).

Taken together, these articles strongly link IL-6-STAT3 signaling with MGMT expression and methylation and to temozolomide sensitivity. However, further studies are required to investigate the mechanisms of action for the epigenetic control of tumour cell functions by IL-6. Overall, it would be advantageous to extensively study the potential of IL-6/STAT3 inhibitors on MGMT expression levels, and determine if this could potentially aid in overcoming temozolomide resistance in glioblastoma considering that MGMT requires STAT3 activation to modulate cellular levels of MGMT. 


\section{Conclusions}

Understanding how overexpressed or over-active signalling pathways promote recurrent glioblastoma progression may lead to the development of new therapies. In particular, targeting the important IL-6-JAK/STAT3 signaling pathway should result in reduced tumour proliferation and invasion and improved patient outcomes. In addition, therapeutic targeting of STAT3 and its components may provide a basis for sensitising these recurrent tumours to the currently available treatments for glioma. For this strategy to proceed, further preclinical research into how IL-6-STAT3 promotes glioblastoma recurrence and progression is still required.

\section{Acknowledgements}

Not applicable.

\section{Funding}

RBL is a mid-career fellowship holder with the Victorian Cancer Agency (grant no. MCRF 15017).

\section{Availability of data and materials}

The datasets used and/or analyzed during the current study are available from the corresponding author on reasonable request.

\section{Authors' contributions}

AJW, VT and RBL contributed to the writing of this manuscript, while HPTN, SSS, APM, AHK and RBL contributed the conception design and editing of the manuscript.

\section{Ethics approval and consent to participate}

Not applicable.

\section{Consent for publication}

Not applicable.

\section{Competing interests}

The authors declare that there are no competing interests.

\section{References}

1. Aldape K, Zadeh G, Mansouri S, Reifenberger G and von Deimling A: Glioblastoma: Pathology, molecular mechanisms and markers. Acta Neuropathol 129: 829-848, 2015.

2. Agnihotri S, Burrell KE, Wolf A, Jalali S, Hawkins C, Rutka JT and Zadeh G: Glioblastoma, a brief review of history, molecular genetics, animal models and novel therapeutic strategies. Arch Immunol Ther Exp (Warsz) 61: 25-41, 2013.

3. Wen PY and Kesari S: Malignant gliomas in adults. N Engl J Med 359: 492-507, 2008.

4. Stupp R, Mason WP, van den Bent MJ, Weller M, Fisher B, Taphoorn MJ, Belanger K, Brandes AA, Marosi C, Bogdahn U, et al: Radiotherapy plus concomitant and adjuvant temozolomide for glioblastoma. N Engl J Med 352: 987-996, 2005.

5. Tully PA, Gogos AJ, Love C, Liew D, Drummond KJ and Morokoff AP: Reoperation for recurrent glioblastoma and its association with survival benefit. Neurosurgery 79: 678-689, 2016.
6. Desbaillets I, Diserens AC, Tribolet N, Hamou MF and Van Meir EG: Upregulation of interleukin 8 by oxygen-deprived cells in glioblastoma suggests a role in leukocyte activation, chemotaxis, and angiogenesis. J Exp Med 186: 1201-1212, 1997.

7. Shan Y, He X, Song W, Han D, Niu J and Wang J: Role of IL-6 in the invasiveness and prognosis of glioma. Int J Clin Exp Med 8: 9114-9120, 2015.

8. Jarnicki A, Putoczki T and Ernst M: Stat3: Linking inflammation to epithelial cancer-more than a 'gut' feeling? Cell Div 5: $14,2010$.

9. Kumari N, Dwarakanath BS, Das A and Bhatt AN: Role of interleukin-6 in cancer progression and therapeutic resistance. Tumour Biol 37: 11553-11572, 2016.

10. Iliopoulos D, Hirsch HA and Struhl K: An epigenetic switch involving NF-kappaB, Lin28, Let-7 MicroRNA, and IL6 links inflammation to cell transformation. Cell 139: 693-706, 2009.

11. Akira S and Kishimoto T: IL-6 and NF-IL6 in acute-phase response and viral infection. Immunol Rev 127: 25-50, 1992.

12. Wu CT, Chen MF, Chen WC and Hsieh CC: The role of IL-6 in the radiation response of prostate cancer. Radiat Oncol 8: 159, 2013.

13. Yang R, Lin Q, Gao HB and Zhang P: Stress-related hormone norepinephrine induces interleukin-6 expression in GES-1 cells. Braz J Med Biol Res 47: 101-109, 2014.

14. Scheller J, Chalaris A, Schmidt-Arras D and Rose-John S: The pro- and anti-inflammatory properties of the cytokine interleukin-6. Biochim Biophys Acta 1813: 878-888, 2011.

15. Gruys E, Toussaint MJ, Niewold TA and Koopmans SJ: Acute phase reaction and acute phase proteins. J Zhejiang Univ Sci B 6: 1045-1056, 2005.

16. Tilg H, Trehu E, Atkins MB, Dinarello CA and Mier JW: Interleukin-6 (IL-6) as an anti-inflammatory cytokine: Induction of circulating IL-1 receptor antagonist and soluble tumor necrosis factor receptor p55. Blood 83: 113-118, 1994.

17. Aderka D, Le JM and Vilcek J: IL-6 inhibits lipopolysaccharide-induced tumor necrosis factor production in cultured human monocytes, U937 cells, and in mice. J Immunol 143: 3517-3523, 1989.

18. Jones SA, Scheller J and Rose-John S: Therapeutic strategies for the clinical blockade of IL-6/gp130 signaling. J Clin Invest 121: 3375-3383, 2011.

19. Mihara M, Hashizume M, Yoshida H, Suzuki M and Shiina M: IL-6/IL-6 receptor system and its role in physiological and pathological conditions. Clin Sci (Lond) 122: 143-159, 2012.

20. Goswami S, Gupta A and Sharma SK: Interleukin-6-mediated autocrine growth promotion in human glioblastoma multiforme cell line U87MG. J Neurochem 71: 1837-1845, 1998.

21. Taga T and Kishimoto T: Gp130 and the interleukin- 6 family of cytokines. Annu Rev Immunol 15: 797-819, 1997.

22. Chalaris A, Garbers C, Rabe B, Rose-John S and Scheller J: The soluble interleukin 6 receptor: Generation and role in inflammation and cancer. Eur J Cell Biol 90: 484-494, 2011.

23. Jones SA, Horiuchi S, Topley N, Yamamoto N and Fuller GM: The soluble interleukin 6 receptor: Mechanisms of production and implications in disease. FASEB J 15: 43-58, 2001.

24. Yoshida K, Taga T, Saito M, Suematsu S, Kumanogoh A, Tanaka T, Fujiwara H, Hirata M, Yamagami T, Nakahata T, et al: Targeted disruption of gp130, a common signal transducer for the interleukin 6 family of cytokines, leads to myocardial and hematological disorders. Proc Natl Acad Sci USA 93: 407-411, 1996.

25. Yeung YT, McDonald KL, Grewal T and Munoz L: Interleukins in glioblastoma pathophysiology: Implications for therapy. Br J Pharmacol 168: 591-606, 2013.

26. Rolhion C, Penault-Llorca F, Kémény JL, Lemaire JJ, Jullien C, Labit-Bouvier C, Finat-Duclos F and Verrelle P: Interleukin-6 overexpression as a marker of malignancy in human gliomas. J Neurosurg 94: 97-101, 2001.

27. Tchirkov A, Khalil T, Chautard E, Mokhtari K, Véronèse L, Irthum B, Vago P, Kémény JL and Verrelle P: Interleukin-6 gene amplification and shortened survival in glioblastoma patients. $\mathrm{Br}$ J Cancer 96: 474-476, 2007.

28. Kudo M, Jono H, Shinriki S, Yano S, Nakamura H, Makino K, Hide T, Muta D, Ueda M, Ota K, et al: Antitumor effect of humanized anti-interleukin-6 receptor antibody (tocilizumab) on glioma cell proliferation. Laboratory investigation. J Neurosurg 111: 219-225, 2009.

29. Van Meir E, Sawamura Y, Diserens AC, Hamou MF and de Tribolet N: Human glioblastoma cells release interleukin 6 in vivo and in vitro. Cancer Res 50: 6683-6688, 1990 
30. Ashizawa T, Miyata H, Iizuka A, Komiyama M, Oshita C, Kume A, Nogami M, Yagoto M, Ito I, Oishi T, et al: Effect of the STAT3 inhibitor STX-0119 on the proliferation of cancer stem-like cells derived from recurrent glioblastoma. Int J Oncol 43: 219-227, 2013.

31. Zhong Z, Wen Z and Darnell JE Jr: Stat3 and Stat4: Members of the family of signal transducers and activators of transcription. Proc Natl Acad Sci USA 91: 4806-4810, 1994.

32. Bromberg JF, Horvath CM, Besser D, Lathem WW and Darnell JE Jr: Stat3 activation is required for cellular transformation by v-src. Mol Cell Biol 18: 2553-2558, 1998.

33. Ouédraogo ZG, Biau J, Kemeny JL, Morel L, Verrelle P and Chautard E: Role of STAT3 in genesis and progression of human malignant gliomas. Mol Neurobiol 54: 5780-5797, 2017.

34. Smilowitz HM, Weissenberger J, Weis J, Brown JD, O'Neill RJ and Laissue JA: Orthotopic transplantation of v-src-expressing glioma cell lines into immunocompetent mice: Establishment of a new transplantable in vivo model for malignant glioma. J Neurosurg 106: 652-659, 2007.

35. Dechow TN, Pedranzini L, Leitch A, Leslie K, Gerald WL, Linkov I and Bromberg JF: Requirement of matrix metalloproteinase-9 for the transformation of human mammary epithelial cells by Stat3-C. Proc Natl Acad Sci USA 101: 10602-10607, 2004

36. Turkson J, Bowman T, Garcia R, Caldenhoven E, De Groot RP and Jove R: Stat 3 activation by Src induces specific gene regulation and is required for cell transformation. Mol Cell Biol 18 2545-2552, 1998.

37. Catlett-Falcone R, Landowski TH, Oshiro MM, Turkson J, Levitzki A, Savino R, Ciliberto G, Moscinski L, Fernández-Luna JL, Nuñez G, et al: Constitutive activation of Stat3 signaling confers resistance to apoptosis in human U266 myeloma cells. Immunity 10: 105-115, 1999.

38. Grandis JR, Drenning SD, Chakraborty A, Zhou MY, Zeng Q, Pitt AS and Tweardy DJ: Requirement of Stat 3 but not Stat 1 activation for epidermal growth factor receptor- mediated cell growth in vitro. J Clin Invest 102: 1385-1392, 1998

39. Rahaman SO, Harbor PC, Chernova O, Barnett GH, Vogelbaum MA and Haque SJ: Inhibition of constitutively active Stat 3 suppresses proliferation and induces apoptosis in glioblastoma multiforme cells. Oncogene 21: 8404-8413, 2002.

40. Sherry MM, Reeves A, Wu JK and Cochran BH: STAT3 is required for proliferation and maintenance of multipotency in glioblastoma stem cells. Stem Cells 27: 2383-2392, 2009.

41. Kohsaka S, Wang L, Yachi K, Mahabir R, Narita T, Itoh T, Tanino M, Kimura T, Nishihara $\mathrm{H}$ and Tanaka S: STAT3 inhibition overcomes temozolomide resistance in glioblastoma by downregulating MGMT expression. Mol Cancer Ther 11: $1289-1299,2012$

42. Heimberger AB: The therapeutic potential of inhibitors of the signal transducer and activator of transcription 3 for central nervous system malignancies. Surg Neurol Int 2: 163, 2011.

43. Waldner MJ, Foersch S and Neurath MF: Interleukin-6-a key regulator of colorectal cancer development. Int J Biol Sci 8 : 1248-1253, 2012.

44. Culig Z and Puhr M: Interleukin-6: A multifunctional targetable cytokine in human prostate cancer. Mol Cell Endocrinol 360 : 52-58, 2012.

45. Dethlefsen C, Højfeldt G and Hojman P: The role of intratumoral and systemic IL-6 in breast cancer. Breast Cancer Res Treat 138: 657-664, 2013

46. Macciò A and Madeddu C: The role of interleukin-6 in the evolution of ovarian cancer: Clinical and prognostic implications-a review. J Mol Med (Berl) 91: 1355-1368, 2013.

47. Miura T, Mitsunaga S, Ikeda M, Shimizu S, Ohno I, Takahashi H, Furuse J, Inagaki M, Higashi S, Kato H, et al: Characterization of patients with advanced pancreatic cancer and high serum interleukin-6 levels. Pancreas 44: 756-763, 2015.

48. Chang CH, Hsiao CF, Yeh YM, Chang GC, Tsai YH, Chen YM, Huang MS, Chen HL, Li YJ, Yang PC, et al: Circulating interleukin-6 level is a prognostic marker for survival in advanced nonsmall cell lung cancer patients treated with chemotherapy. Int J Cancer 132: 1977-1985, 2013.

49. Wei LH, Kuo ML, Chen CA, Chou CH, Lai KB, Lee CN and Hsieh CY: Interleukin-6 promotes cervical tumor growth by VEGF-dependent angiogenesis via a STAT3 pathway. Oncogene 22: 1517-1527, 2003

50. Weissenberger J, Loeffler S, Kappeler A, Kopf M, Lukes A, Afanasieva TA, Aguzzi A and Weis J: IL- 6 is required for glioma development in a mouse model. Oncogene 23: 3308-3316, 2004 .
51. Liu Q, Li G, Li R, Shen J, He Q, Deng L, Zhang C and Zhang J: IL-6 promotion of glioblastoma cell invasion and angiogenesis in U251 and T98G cell lines. J Neurooncol 100: 165-176, 2010.

52. Li R, Li G, Deng L, Liu Q, Dai J, Shen J and Zhang J: IL-6 augments the invasiveness of U87MG human glioblastoma multiforme cells via up-regulation of MMP-2 and fascin-1. Oncol Rep 23: 1553-1559, 2010.

53. Anton K, Banerjee D and Glod J: Macrophage-associated mesenchymal stem cells assume an activated, migratory, pro-inflammatory phenotype with increased IL- 6 and CXCL10 secretion. PLoS One 7: e35036, 2012.

54. Carmeliet P: Angiogenesis in life, disease and medicine. Nature 438: 932-936, 2005.

55. Garonna E, Botham KM, Birdsey GM, Randi AM, Gonzalez-Perez RR and Wheeler-Jones CP: Vascular endothelial growth factor receptor-2 couples cyclo-oxygenase- 2 with pro-angiogenic actions of leptin on human endothelial cells. PLoS One 6: e18823, 2011.

56. Shibuya M: Vascular endothelial growth factor and its receptor system: Physiological functions in angiogenesis and pathological roles in various diseases. J Biochem 153: 13-19, 2013.

57. Labussière M, Cheneau C, Prahst C, Gállego Pérez-Larraya J, Farina P, Lombardi G, Mokhtari K, Rahimian A, Delattre JY, Eichmann A and Sanson M: Angiopoietin-2 may be involved in the resistance to bevacizumab in recurrent glioblastoma. Cancer Invest 34: 39-44, 2016.

58. Zhou YH, Tan F, Hess KR and Yung WK: The expression of PAX6, PTEN, vascular endothelial growth factor, and epidermal growth factor receptor in gliomas: relationship to tumor grade and survival. Clin Cancer Res 9: 3369-3375, 2003.

59. Bergers G and Hanahan D: Modes of resistance to anti-angiogenic therapy. Nat Rev Cancer 8: 592-603, 2008.

60. Takano S: Glioblastoma angiogenesis: VEGF resistance solutions and new strategies based on molecular mechanisms of tumor vessel formation. Brain Tumor Pathol 29: 73-86, 2012.

61. Li JL, Sainson RC, Oon CE, Turley H, Leek R, Sheldon H, Bridges E, Shi W, Snell C, Bowden ET, et al: DLL4-Notch signaling mediates tumor resistance to anti-VEGF therapy in vivo. Cancer Res 71: 6073-6083, 2011.

62. Peterson TE, Kirkpatrick ND, Huang Y, Farrar CT, Marijt KA, Kloepper J, Datta M, Amoozgar Z, Seano G, Jung K, et al: Dual inhibition of Ang-2 and VEGF receptors normalizes tumor vasculature and prolongs survival in glioblastoma by altering macrophages. Proc Natl Acad Sci USA 113: 4470-4475, 2016

63. Tabouret E, Denicolai E, Delfino C, Graillon T, Boucard C, Nanni I, Padovani L, Figarella-Branger D and Chinot O: Changes in PlGF and MET-HGF expressions in paired initial and recurrent glioblastoma. J Neurooncol 130: 431-437, 2016.

64. Piao Y, Liang J, Holmes L, Henry V, Sulman E and de Groot JF: Acquired resistance to anti-VEGF therapy in glioblastoma is associated with a mesenchymal transition. Clin Cancer Res 19: 4392-4403, 2013.

65. Wesche J, Haglund K and Haugsten EM: Fibroblast growth factors and their receptors in cancer. Biochem J 437: 199-213, 2011.

66. Fu Z, Chen X, Guan S, Yan Y, Lin H and Hua ZC: Curcumin inhibits angiogenesis and improves defective hematopoiesis induced by tumor-derived VEGF in tumor model through modulating VEGF-VEGFR2 signaling pathway. Oncotarget 6: 19469-19482, 2015.

67. Wu XY, Xu H, Wu ZF, Chen C, Liu JY, Wu GN, Yao XQ, Liu FK, Li G and Shen L: Formononetin, a novel FGFR2 inhibitor, potently inhibits angiogenesis and tumor growth in preclinical models. Oncotarget 6: 44563-44578, 2015.

68. Waxman AB and Kolliputi N: IL-6 protects against hyperoxia-induced mitochondrial damage via Bcl-2-induced Bak interactions with mitofusins. Am J Respir Cell Mol Biol 41: 385-396, 2009.

69. Hirano T, Ishihara K and Hibi M: Roles of STAT3 in mediating the cell growth, differentiation and survival signals relayed through the IL-6 family of cytokine receptors. Oncogene 19: 2548-2556, 2000.

70. Gritsko T, Williams A, Turkson J, Kaneko S, Bowman T, Huang M, Nam S, Eweis I, Diaz N, Sullivan D, et al: Persistent activation of stat 3 signaling induces survivin gene expression and confers resistance to apoptosis in human breast cancer cells. Clin Cancer Res 12: 11-19, 2006.

71. Bonnet D and Dick JE: Human acute myeloid leukemia is organized as a hierarchy that originates from a primitive hematopoietic cell. Nat Med 3: 730-737, 1997.

72. Clarke MF and Fuller M: Stem cells and cancer: Two faces of eve. Cell 124: 1111-1115, 2006. 
73. Lapidot T, Sirard C, Vormoor J, Murdoch B, Hoang T, Caceres-Cortes J, Minden M, Paterson B, Caligiuri MA and Dick JE: A cell initiating human acute myeloid leukaemia after transplantation into SCID mice. Nature 367: 645-648, 1994.

74. Magee JA, Piskounova E and Morrison SJ: Cancer stem cells: Impact, heterogeneity, and uncertainty. Cancer Cell 21: 283-296, 2012.

75. Visvader JE and Lindeman GJ: Cancer stem cells in solid tumours: Accumulating evidence and unresolved questions. Nat Rev Cancer 8: 755-768, 2008

76. Willyard C: Stem cells: Bad seeds. Nature 498: S12-S13, 2013.

77. Galli R, Binda E, Orfanelli U, Cipelletti B, Gritti A, De Vitis S, Fiocco R, Foroni C, Dimeco F and Vescovi A: Isolation and characterization of tumorigenic, stem-like neural precursors from human glioblastoma. Cancer Res 64: 7011-7021, 2004.

78. Singh SK, Clarke ID, Terasaki M, Bonn VE, Hawkins C, Squire J and Dirks PB: Identification of a cancer stem cell in human brain tumors. Cancer Res 63: 5821-5828, 2003.

79. Hossain A, Gumin J, Gao F, Figueroa J, Shinojima N, Takezaki T, Priebe W, Villarreal D, Kang SG, Joyce C, et al: Mesenchyma stem cells isolated from human gliomas increase proliferation and maintain stemness of glioma stem cells through the IL-6/gp130/STAT3 pathway. Stem Cells 33: 2400-2415, 2015.

80. Jafri NF, Clarke JL, Weinberg V, Barani IJ and Cha S: Relationship of glioblastoma multiforme to the subventricular zone is associated with survival. Neuro Oncol 15: 91-96, 2013.

81. Young GS, Macklin EA, Setayesh K, Lawson JD, Wen PY, Norden AD, Drappatz J and Kesari S: Longitudinal MRI evidence for decreased survival among periventricular glioblastoma. J Neurooncol 104: 261-269, 2011

82. Kroon P, Berry PA, Stower MJ, Rodrigues G, Mann VM, Simms M, Bhasin D, Chettiar S, Li C, Li PK, et al: JAK-STAT blockade inhibits tumor initiation and clonogenic recovery of prostate cancer stem-like cells. Cancer Res 73: 5288-5298, 2013.

83. Marotta LL, Almendro V, Marusyk A, Shipitsin M, Schemme J, Walker SR, Bloushtain-Qimron N, Kim JJ, Choudhury SA, Maruyama R, et al: The JAK2/STAT3 signaling pathway is required for growth of $\mathrm{CD} 44^{+} \mathrm{CD} 24$-stem cell-like breast cancer cells in human tumors. J Clin Invest 121: 2723-2735, 2011

84. Schroeder A, Herrmann A, Cherryholmes G, Kowolik C, Buettner R, Pal S, Yu H, Müller-Newen G and Jove R: Loss of androgen receptor expression promotes a stem-like cell phenotype in prostate cancer through STAT3 signaling. Cancer Res 74: 1227-1237, 2014

85. Zhou B, Damrauer JS, Bailey ST, Hadzic T, Jeong Y, Clark K, Fan C, Murphy L, Lee CY, Troester MA, et al: Erythropoietin promotes breast tumorigenesis through tumor-initiating cell self-renewal. J Clin Invest 124: 553-563, 2014

86. Guo X, Qiu J, Tu T, Yang X, Deng L, Anders RA, Zhou L and Fu YX: Induction of innate lymphoid cell-derived interleukin-22 by the transcription factor STAT3 mediates protection against intestinal infection. Immunity 40: 25-39, 2014.

87. Wang H, Lathia JD, Wu Q, Wang J, Li Z, Heddleston JM, Eyler CE, Elderbroom J, Gallagher J, Schuschu J, et al: Targeting interleukin 6 signaling suppresses glioma stem cell survival and tumor growth. Stem Cells 27: 2393-2404, 2009.

88. Giladi ND, Ziv-Av A, Lee HK, Finniss S, Cazacu S, Xiang C, Waldman Ben-Asher H, deCarvalho A, Mikkelsen T, Poisson L and Brodie C: RTVP-1 promotes mesenchymal transformation of glioma via a STAT-3/IL-6-dependent positive feedback loop. Oncotarget 6: 22680-22697, 2015.

89. Li GH, Wei H, Lv SQ, Ji H and Wang DL: Knockdown of STAT3 expression by RNAi suppresses growth and induces apoptosis and differentiation in glioblastoma stem cells. Int J Oncol 37: 103-110, 2010.

90. Yu H, Lee H, Herrmann A, Buettner R and Jove R: Revisiting STAT3 signalling in cancer: New and unexpected biological functions. Nat Rev Cancer 14: 736-746, 2014.

91. Jackson C, Ruzevick J, Amin AG and Lim M: Potential role for STAT3 inhibitors in glioblastoma. Neurosurg Clin N Am 23: 379-389, 2012

92. Chang Q, Bournazou E, Sansone P, Berishaj M, Gao SP, Daly L, Wels J, Theilen T, Granitto S, Zhang X, et al: The IL-6/JAK/Stat3 feed-forward loop drives tumorigenesis and metastasis. Neoplasia 15: 848-862, 2013.

93. Liang Q, Ma C, Zhao Y, Gao G and Ma J: Inhibition of STAT3 reduces astrocytoma cell invasion and constitutive activation of STAT3 predicts poor prognosis in human astrocytoma. PLoS One 8: e84723, 2013
94. Bowman T, Broome MA, Sinibaldi D, Wharton W, Pledger WJ, Sedivy JM, Irby R, Yeatman T, Courtneidge SA and Jove R: Stat3-mediated Myc expression is required for Src transformation and PDGF-induced mitogenesis. Proc Natl Acad Sci USA 98: 7319-7324, 2001.

95. Hodge DR, Hurt EM and Farrar WL: The role of IL-6 and STAT3 in inflammation and cancer. Eur J Cancer 41: 2502-2512, 2005.

96. Kortylewski M and Yu H: Stat3 as a potential target for cancer immunotherapy. J Immunother 30: 131-139, 2007.

97. Yu CL, Meyer DJ, Campbell GS, Larner AC, Carter-Su C, Schwartz J and Jove R: Enhanced DNA-binding activity of a Stat3-related protein in cells transformed by the Src oncoprotein. Science 269: 81-83, 1995

98. Zhong Z, Wen Z and Darnell JE Jr: Stat3: A STAT family member activated by tyrosine phosphorylation in response to epidermal growth factor and interleukin-6. Science 264: 95-98, 1994.

99. Elliott LH, Brooks WH and Roszman TL: Inability of mitogen-activated lymphocytes obtained from patients with malignant primary intracranial tumors to express high affinity interleukin 2 receptors. J Clin Invest 86: 80-86, 1990.

100. Fletcher S, Drewry JA, Shahani VM, Page BD and Gunning PT: Molecular disruption of oncogenic signal transducer and activator of transcription 3 (STAT3) protein. Biochem Cell Biol 87: $825-833,2009$.

101. Jing $\mathrm{N}$ and Tweardy DJ: Targeting Stat3 in cancer therapy. Anticancer Drugs 16: 601-607, 2005.

102. Leeman RJ, Lui VW and Grandis JR: STAT3 as a therapeutic target in head and neck cancer. Expert Opin Biol Ther 6: 231-241, 2006

103. Heinrich PC, Behrmann I, Müller-Newen G, Schaper F and Graeve L: Interleukin-6-type cytokine signalling through the gp130/Jak/STAT pathway. Biochem J 334: 297-314, 1998.

104. Kim SR, Bae MK, Kim JY, Wee HJ, Yoo MA and Bae SK: Aspirin induces apoptosis through the blockade of IL-6-STAT3 signaling pathway in human glioblastoma A172 cells. Biochem Biophys Res Commun 387: 342-347, 2009.

105. Shao H, Cheng HY, Cook RG and Tweardy DJ: Identification and characterization of signal transducer and activator of transcription 3 recruitment sites within the epidermal growth factor receptor. Cancer Res 63: 3923-3930, 2003.

106. Abou-Ghazal M, Yang DS, Qiao W, Reina-Ortiz C, Wei J, Kong LY, Fuller GN, Hiraoka N, Priebe W, Sawaya R and Heimberger AB: The incidence, correlation with tumor-infiltrating inflammation, and prognosis of phosphorylated STAT3 expression in human gliomas. Clin Cancer Res 14: 8228-8235, 2008.

107. Tu Y,Zhong Y, Fu J, Cao Y, Fu G, Tian X and Wang B: Activation of JAK/STAT signal pathway predicts poor prognosis of patients with gliomas. Med Oncol 28: 15-23, 2011.

108. Minniti G, Muni R, Lanzetta G, Marchetti P and Enrici RM: Chemotherapy for glioblastoma: Current treatment and future perspectives for cytotoxic and targeted agents. Anticancer Res 29: 5171-5184, 2009.

109. Baer JC, Freeman AA, Newlands ES, Watson AJ, Rafferty JA and Margison GP: Depletion of O6-alkylguanine-DNA alkyltransferase correlates with potentiation of temozolomide and CCNU toxicity in human tumour cells. Br J Cancer 67: 1299-1302, 1993.

110. Wang G, Weiss C, Sheng P and Bresnick E: Retrovirus-mediated transfer of the human O6-methylguanine-DNA methyltransferase gene into a murine hematopoietic stem cell line and resistance to the toxic effects of certain alkylating agents. Biochem Pharmacol 51: 1221-1218, 1996.

111. Hegi ME, Diserens AC, Gorlia T, Hamou MF, de Tribolet N, Weller M, Kros JM, Hainfellner JA, Mason W, Mariani L, et al: MGMT gene silencing and benefit from temozolomide in glioblastoma. N Engl J Med 352: 997-1003, 2005.

112. Piperi C, Themistocleous MS, Papavassiliou GA, Farmaki E, Levidou G, Korkolopoulou P, Adamopoulos C and Papavassiliou AG: High incidence of MGMT and RARbeta promoter methylation in primary glioblastomas: Association with histopathological characteristics, inflammatory mediators and clinical outcome. Mol Med 16: 1-9, 2010.

113. Giometto B, Bozza F, Faresin F, Alessio L, Mingrino S and Tavolato B: Immune infiltrates and cytokines in gliomas. Acta Neurochir (Wien) 138: 50-56, 1996.

114. Chang CY, Li MC, Liao SL, Huang YL, Shen CC and Pan HC: Prognostic and clinical implication of IL-6 expression in glioblastoma multiforme. J Clin Neurosci 12: 930-933, 2005 
115. Sasaki A, Ishiuchi S, Kanda T, Hasegawa M and Nakazato Y: Analysis of interleukin- 6 gene expression in primary human gliomas, glioblastoma xenografts, and glioblastoma cell lines. Brain Tumor Pathol 18: 13-21, 2001.

116. Hussain SF, Kong LY, Jordan J, Conrad C, Madden T, Fokt I, Priebe $\mathrm{W}$ and Heimberger AB: A novel small molecule inhibitor of signal transducers and activators of transcription 3 reverses immune tolerance in malignant glioma patients. Cancer Res 67 9630-9636, 2007.

117. Iwamaru A, Szymanski S, Iwado E, Aoki H, Yokoyama T, Fokt I, Hess K, Conrad C, Madden T, Sawaya R, et al: A novel inhibitor of the STAT3 pathway induces apoptosis in malignant glioma cells both in vitro and in vivo. Oncogene 26: 2435-2444, 2007.

118. Stechishin OD, Luchman HA, Ruan Y, Blough MD, Nguyen SA, Kelly JJ, Cairncross JG and Weiss S: On-target JAK2/STAT3 inhibition slows disease progression in orthotopic xenografts of human glioblastoma brain tumor stem cells. Neuro Oncol 15: 198-207, 2013

119. McFarland BC, Ma JY, Langford CP, Gillespie GY, Yu H, Zheng Y, Nozell SE, Huszar D and Benveniste EN: Therapeutic potential of AZD1480 for the treatment of human glioblastoma. Mol Cancer Ther 10: 2384-2393, 2011.

120. He K, Qi Q, Chan CB, Xiao G, Liu X, Tucker-Burden C, Wang L, Mao H, Lu X, McDonald FE, et al: Blockade of glioma proliferation through allosteric inhibition of JAK2. Sci Signal 6: ra55, 2013

121. Senft C, Priester M, Polacin M, Schröder K, Seifert V, Kögel D and Weissenberger J: Inhibition of the JAK-2/STAT3 signaling pathway impedes the migratory and invasive potential of human glioblastoma cells. J Neurooncol 101: 393-403, 2011.

122. Lo HW, Cao X, Zhu H and Ali-Osman F: Constitutively activated STAT3 frequently coexpresses with epidermal growth factor receptor in high-grade gliomas and targeting STAT3 sensitizes them to Iressa and alkylators. Clin Cancer Res 14: 6042-6054, 2008.
123. Mukthavaram R, Ouyang X, Saklecha R, Jiang P, Nomura N, Pingle SC, Guo F, Makale $M$ and Kesari S: Effect of the JAK2/STAT3 inhibitor SAR317461 on human glioblastoma tumorspheres. J Transl Med 13: 269, 2015.

124. Fuh B, Sobo M, Cen L, Josiah D, Hutzen B, Cisek K, Bhasin D, Regan N, Lin L, Chan C, et al: LLL-3 inhibits STAT3 activity, suppresses glioblastoma cell growth and prolongs survival in a mouse glioblastoma model. Br J Cancer 100: 106-112, 2009.

125. Ball S, Li C, Li PK and Lin J: The small molecule, LLL12, inhibits STAT3 phosphorylation and induces apoptosis in medulloblastoma and glioblastoma cells. PLoS One 6: e18820, 2011.

126. Sai K, Wang S, Balasubramaniyan V, Conrad C, Lang FF, Aldape K, Szymanski S, Fokt I, Dasgupta A, Madden T, et al: Induction of cell-cycle arrest and apoptosis in glioblastoma stem-like cells by WP1193, a novel small molecule inhibitor of the JAK2/STAT3 pathway. J Neurooncol 107: 487-501, 2012.

127. Han TJ, Cho BJ, Choi EJ, Kim DH, Song SH, Paek SH and Kim IA: Inhibition of STAT3 enhances the radiosensitizing effect of temozolomide in glioblastoma cells in vitro and in vivo. J Neurooncol 130: 89-98, 2016.

This work is licensed under a Creative Commons Attribution-NonCommercial-NoDerivatives 4.0 International (CC BY-NC-ND 4.0) License. 